\title{
FAMILY CENTERED ROUNDS APPRECIATED BY HEALTHCARE PROFESSIONALS
}

Bas van Oort, Margo Jansen, Veerle Wille, Marloes Bonnema, Jolanda Maaskant ACHIEVE Centre of Applied Research, Faculty of Health, Amsterdam University of Applied Sciences, Amsterdam, the Netherlands Emma Children's Hospital, Amsterdam UMC, Amsterdam, the Netherlands

p.j.s.oort@hva.nl

\section{Introduction}

Participation in daily medical rounds seems to be an outstanding moment to improve parents' involvement in the care and decisionmaking process of their hospit alized child.

We investigated the opinions of healthcare professionals during the implementation of Family Centered Rounds (FCRs).

\section{Methods}

A survey was undertaken among paediatricians and paediatric nurses by means of a questionnaire with five questions. The survey was enriched with narrative data. Dat a were collected before st art of the implementation, and after six and twelve months.

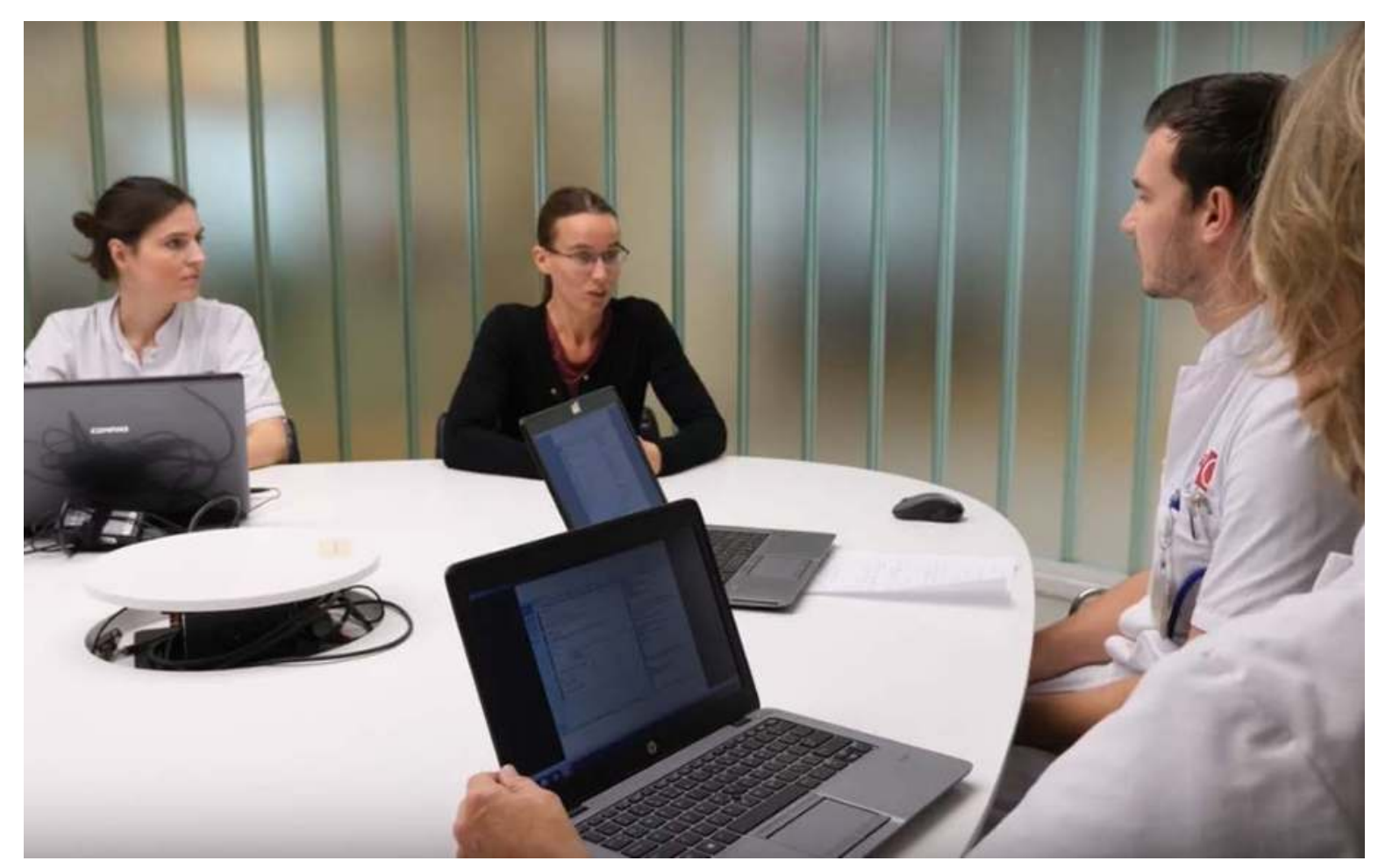

Results

From the pre-intervention period 144 and from the post-intervention 164 questionnaires were analyzed (response rate $85 \%$ and $76 \%$ ). The results are shown in the table below. A second survey after 12 months showed the results sust ainded.

1. Questions about child and family get answered during medical rounds.

before after

2. We work as a team for the child and its family.

3,92

4,15

3. The plan of care for the upcoming $24 \mathrm{hrs}$ is clear.

4,08

4,24

4. Parents know their child best; we make good use of their knowledge.

3,47

3,75

5. We can speak out freely during medical rounds.

3,35

4,08

Mean scores on a 5-point Likert scale; higher scores indicate a more positive opinion. All differences between pre-intervention and post-

3,38

intervention periods: $p<0.05$.

"We believe we cannot speak out freely, but I wonder if this is true. My experience is that I can discuss everything with parent s present
Conclusion

Active participation of parents in medical rounds seems to result in better teamwork and information exchange. 